Arnaldo BORDONI

\title{
New data on the Oriental Xantholinini 39. New species and new records from the Philippines
}

\author{
(Coleoptera, Staphylinidae)
}

\section{$267^{\text {th }}$ contribution to the knowledge of the Staphylinidae}

\begin{abstract}
Riassunto: Nuovi dati su Xantholinini orientali. 39. Nuove specie e nuovi dati dalle Filippine (Coleoptera, Staphylinidae). Vengono descritte le seguenti specie ritrovate presso le indicate isole delle Filippine: Metolinus finettii sp. n. (Palawan), M. cleopatranus sp. $\mathrm{n}$. (Palawan), M. elegans sp. n. (Mindanao), M. insularis sp. n. (Mindanao), Erymus elytratus sp. n. (Mindanao), Xanthophius philippinus sp. $\mathrm{n}$. (Panay), Manilla rufula sp. n. (Mindanao), M. maramag sp. n. (Mindanao). Vengono altresì elencate le seguenti specie, nuove per le isole delle Filippine: Ulisseus dispilus (Erichson, 1839) (Panay, Mindanao), Thyreocephalus hongkongensis (Redtenbacher, 1867) (Palawan), Thyreocephalus rufus Cameron, 1941 (Negros); Thyreocephalus omaleus Bordoni, 2002 (Luzon), Thyreocephalus dustucheus Bordoni, 2002 (Mindanao), Metolinus libertatis Bordoni, 2002 (Negros); Phacophallus pallidipennis (Motschulsky, 1858) (Palawan).
\end{abstract}

\begin{abstract}
The following species are described from the listed islands of the Philippines: Metolinus finettii sp. n. (Palawan), M. cleopatranus sp. n. (Palawan), M. elegans sp. n. (Mindanao), M. insularis sp. n. (Mindanao), Erymus elytratus sp. n. (Mindanao), Xanthophius philippinus sp. n. (Panay), Manilla rufula sp. n. (Mindanao), M. maramag sp. n. (Mindanao). New records are listed. The following species are new records for the listed islands: Ulisseus dispilus (Erichson, 1839) (Panay, Mindanao), Thyreocephalus hongkongensis (Redtenbacher, 1867) (Palawan), Thyreocephalus rufus Cameron, 1941 (Negros); Thyreocephalus omaleus Bordoni, 2002 (Luzon), Thyreocephalus dustucheus Bordoni, 2002 (Mindanao), Metolinus libertatis Bordoni, 2002 (Negros); Phacophallus pallidipennis (Motschulsky, 1858) (Palawan).
\end{abstract}

Key words: Coleoptera, Staphylinidae, Xantholinini, Metolinus, Erymus, Xanthophius, Manilla, new species, new records, Philippines.

\section{INTRODUCTION}

The Philippine Islands are located between South China and the Greater Sunda Islands and zoogeographically constitute a marginal, geologically complex archipelago that stretches north of Borneo for a thousand miles, just on the edge of the Asian continental shelf. They are tropical islands with many mountainous areas, especially in Luzon and Mindanao, and are part of a Cenozoic relief that connects them with those of the Sunda archipelago.

It seems that these islands have not had prolonged connections during the Pleistocene; this would explain the existence of numerous endemic species. On the other hand it is known that there have been recent immigrations of species from Borneo via the island of Palawan. These islands therefore harbour a rather complex local fauna. The Philippines lie in the tropical zone; northern islands are affected by the monsoon seasons while the southern islands are subjected to equatorial influences.
Despite indiscriminate deforestation, forests still exist, often in a degraded state, with subtropical trees typical of southeastern Asia. It is divided into various rainforest tree floras: Shorea, Dipterocarpus and Hopea forests. Forest of Dipterocarpus warburgii (endemic to Philippines and Borneo in both primary and secondary forests) is restricted to areas of highrainfall. The remaining, very scarce tropical forests, are present in the Sierra Madre in the Oriental portion of Luzon, Samar, northeast of Mindanao and Palawan, while monsoon forests occur in the east of Luzon, Palawan and in the south of Mindanao.

The material I had studied in the revision of the Xantholinini of the Oriental Region (Bordoni, 2002) came mainly from the old collections made Baker and Bötcher and from more recent material collected by Swedish and French colleagues. Until now the known Xatholinini of the Philippines were confined to those mentioned in that revision. Specifically highlighted was the presence of the genus Manilla Bordoni, 1990 with

\footnotetext{
*Arnaldo Bordoni, Museo di Storia Naturale dell’Università di Firenze, Sezione di Zoologia "La Specola”, Via Romana 17, 50125 Florence, Italy. E-mail: arnaldo.bordoni@fastewebnet.it
} 
8 montane species (orousseti Bordoni, 1990, erudra Bordoni, 2002, deharvengi Bordoni, 1990, lafondiana Bordoni, 2002, misamisae Bordoni, 2002, basimaculata Bordoni, 2002, montanella Bordoni, 2002, bipatea Bordoni, 1990, emussitata Bordoni, 1990) and Metolinus Cameron, 1920 with 14 species (hebdomadicus Bordoni, 2002, libertatis Bordoni, 2002, torrevillasi Bordoni, 2002, bombax Bordoni, 2002, hamatilis Bordoni, 2002, heliacus Bordoni, 2002, grandis (Bernhauer, 1919), kibungolanus Bordoni, 2002, dissonus Bordoni, 2002, philippinus (Bernhauer, 1916), apomontis Bordoni, 2002, palawanensis Bordoni, 2002, minutissimus Bordoni, 2002) and Pachycorynus Motschulsky, 1858 with 9 species (bakeri Bernhauer, 1916, montanus Bordoni, 2002, virgineus Bordoni, 2002, fortepunctatus Bordoni, 2002, enricoi Bordoni, 2002, samarensis Bordoni, 2002, cavendishi Bordoni, 2002, longiceps Cameron, 1941, primarius Bordoni, 2002, dimidiatus Motschulsky, 1858).

Also abundant are Thyreocephalus GuérinMéneville, 1844 with 11 species, some of which belong to a characteristic group, formed by endemic taxa on individual islands (hanacolus Bordoni, 2002, boettcheri Bordoni, 2002, hanadesmus Bordoni, 2002, tenuipunctus Bordoni, 2002, bakeri Bordoni, 2002), others, probably sub-corticicolous, have a very flat body (omaleus, Bordoni, 2002 dustucheus Bordoni, 2002), others (philippinus Bernhauer, 1912, albertisi (Fauvel, 1877)) are common to Celebes and the Austromalayan sub-region. The genus Zeteotomus Jacquelin du Val, 1857 (semialbipennis Bordoni, 2002, philippinus (Cameron, 1941), agnosticus Bordoni, 2002, insularis Bordoni, 2002, apomontis Bordoni, 2002, haddeni Bordoni, 2002), seems to have in these islands the northern limit of distribution in the Oriental Region.

Less abundant are species of Spaniolinus Bernhauer, 1916 (raffrayi (Fauvel, 1879), rubidus Bordoni, 2002) (the first also occurs in Celebes, Buru, and Halmahera) as testimony to the ancient link. The Philippines seem to be the current northern limit of distribution of uncommon austromalayan genera such as Tetraulacus Bordoni, 2002 (corticalis Bordoni, 2002, coequatus Bordoni, 2002), Neoxantholinus Cameron, 1944 (drumophilus Bordoni, 2002) and more widely distributed genera, such as Phacophallus, Coiffait, 1956 (papuensis (Fauvel, 1878), which is also known in New Guinea, and Xanthophius Motschulsky, 1859 (benguetensis Bordoni, 2002). These islands are also the northern limit of eastern equatorial genera such as Andelis Bordoni, 2002 (anelpistus Bordoni, 2002) or prevalently Indochinese ones like Indomorphus Bordoni, 2002 (oreinus Bordoni, 2002, ecferus Bordoni, 2002).

The monospecific genus Ulisseus Bordoni, 2002 (dispilus (Erichson, 1839)) appears to have reached the current easternmost limit of distribution in these islands. Finally it is also interesting to note that in this area of exceptional territorial fragmentation and consequent presence of numerous endemic species, only one genus (Nilla Bordoni, 2002) with the species hisamatsui Bordoni, 2002, is endemic to the Philippines.

In conclusion, these islands are home to a rich composite Xantholinine fauna, the vast majority of which are endemic taxa on individual islands, belonging to genera with Indomalese distribution alongside Austromalayan taxa. The Philippines may be the centre of distribution of some of these genera (Manilla, Metolinus, Pachycorynus).

The Philippines harbour one of the richest concentrations of species of Xantholinini in the Oriental Region. Since completing the revision of the Oriental Xantholinini (Bordoni, 2002) however I have seen no new material from the Philippines, so the 62 species known from this islands are those listed in that work; it follows that any new data contribute greatly to the knowledge of the tribes in this area.

The present paper presents the result of the study of extra specimens from various institutions and private collections.

\section{Acronyms}

cB: coll. Bordoni, Firenze, Italy

cI: coll. Ito, Kyoto, Japan

MZF: Museo Zoologico "La Specola” dell'Università, Firenze, Italy

NHMB: Naturhistorishes Museum, Basel, Switzerland

\section{TAXONOMY}

Pachycorynus dimidiatus Motschulsky, 1858

EXAMINED MATERIAL. Philippines, Palawan, Cleopatra Needle N. P., Tanabank riv. val., 300 m, Bolm 2022.XII.1990, 1 ठ, 2 ㅇ (NHMB), 2 오 (cB).

DisTRIBUTION. This species is very widespread in the Oriental Region, including the Philippines (Bordoni, 2002).

Pachycorynus bakeri Bernhauer, 1916

EXAmINED Material. Philippines, Mindanao, Mara- 
mag Prov., Portulin, 1700 m, Bolm 3.I.1991, 2 exx. (NHMB), 1 ex. (cB).

Note. This species was described from Mindanao (Mt Banahao and Momungan) and Luzon (Los Baños). This is the first record since the citation in Bordoni, 2002..

\section{Spaniolinus raffrayi (Fauvel, 1879)}

Examined Material. Philippines, S Luzon, Los Baños, Laguna, I. Lumawig I.2015, 1 ex. (MZF).

Distribution. The species is known from Philippines, Sulawesi and the Moluccas (Bordoni, 2002).

Spaniolinus rubidus Bordoni, 2002

Examined Material. Philippines, Mindanao, $30 \mathrm{~km}$ W Maramag, 1600 m, Bolm 28-30.XII.1990, 1 ठ (NHMB).

Note. The species was described from Mindanao (Mt Kaatoan, Misamis, and Lake Sebu). This is the first record since the description of the species. Spaniolinus rubidus is characterized by the absence of microsculpture on the dorsal and ventral surface of head and by absence of lateral carinae on the head.

Ulisseus dispilus (Erichson, 1839)

EXAMINED MATERIAL. Philippines, SW Panay, $8 \mathrm{~km} \mathrm{E}$ Bontol, 200 m, Bolm 10-11.I.1990, 1 ex. (NHMB); Palawan, Port Barton, 150 m, Bolm 14-18.I.1990, 6 exx. (NHMB), 3 exx. (cB).

Distribution. This species is known from North India, Nepal, Thailand, Laos, Vietnam, Malay Peninsula and the Philippines (Bordoni, 2002). New record for Panay and Palawan.

\section{Thyreocephalus hongkongensis (Redtenbacher, 1867)}

EXamined Material. Philippines, Palawan, Port Barton, 150 m, Bolm 14-18.I.1990, 1 ex. (NHMB); Negros, Mt Canla-on, D. Mohagan I-II.2009, 2 exx. (cI), 1 ex. (cB).

DistRIBUTION. The species is known from many countries in the eastern part of the Oriental Region, from Java and Bali to southern China; in the Philippines it was known from Luzon, Mindoro and Mindanao (Bordoni, 2002). New record for Palawan.

Thyreocephalus rufus Cameron, 1941

EXAMINED MATERIAL. Philippines, Negros, Tagpili, Mahoplag Leyte, D. Mohagan 14.VI.2004, 6 exx. (cI), 2 exx. (cB); Mindanao, 30 km W Maramag, 1600 m, Bolm 28-
30.XII.1990, 1 ex. (NHMB); Mindanao, Maramag Prov., Portulin, 1700 m, Bolm I.1991, 2 exx. (NHMB), 1 ex. (cB); same data, 3.I.1991, 3 exx. (NHMB), 1 ex. (cB); Mindanao, S Cotabato, Kadapawan, I. Lumawig XII.2014, 4 exx. (MZF), 1 ex. (cB); Mindanao, Mizamis Oriental, Balingasag, I. Lumawig XII.2014, 3 exx. (MZF); Mindanao, Agusan del Norte, Esperanza, I. Lumawig XII.2014, 3 exx. (MZF), 1 ex. (cB).

Note. This is an endemic species of the Philippines. New to Negros.

Thyreocephalus annulatus (Fauvel, 1895)

EXAmined MATERIAL. Philippines, C Luzon, Kinabuhayan Vill., T. Itoh 1-6.VIII.1988, 3 exx. (cI), 1 ex. (cB); S Luzon, Quezon N. P. (Lucena), $250 \mathrm{~m}$, Bolm 8-10.I.1991, 5 exx. (NHMB), 2 exx. (cB); S Luzon, Camarines Sur, Ocampo, I. Lumawig I.2015, 2 exx. (MZF); S Luzon, Los Baños, Laguna, I. Lumawig I.2015, 1 ex. (MZF); SE Luzon, Sierra Madre, Quirino, leg. ? IV.2012, 1 ex. (cI); Negros, Mt Canla-on, D. Mohagan I.2009, 3 exx. (cI), 1 ex. (cB). NotE. The species is widespread in the Oriental Region, from Burma to Bali (Bordoni, 2002). The specimens from Philippines are characterized by the dark abdomen.

Thyreocephalus hanacolus Bordoni, 2002

Examined Material. Philippines, Negros, Mt Canlaon, D. Mohagan I-II.2009, 1 ex. (cB).

Distribution. The species was described from Negros (Dumaguete) and seem endemic to this island. This is the first record since the description of the species.

Thyreocephalus dustucheus Bordoni, 2002

EXAMINED MATERIAL. Philippines, S Luzon, Bicol, Camarines Sur, Tigaon, I. Lumaawig I.2015, 1 ex. (cB); Mindanao, Compostela, Masala, I. Lumawig I.2015, 2 exx. (MZF), 1 ex.cB); Mindanao, Bukidnon, Kabanglasan, I. Lumawig XII.2014, 1 ex. (MZF).

Note. This is an endemic Philippine species (Bordoni, 2002). New record for Mindanao. This is the first record since the description of the species. I provide a figure of the head and pronotum (Fig. 1).

Thyreocephalus omaleus Bordoni, 2002

EXAmined Material. Philippines, NE Luzon, Sierra Madre, Quirino, leg. ? IX.2012, 1 ठै (cI); N Luzon, Cagayan, leg. ? VI. 2011, 1 ๙ (cB).

Note. This is an endemic species of the Philippines (Bordoni, 2002). New record for Luzon. This is the first record since the description of the species. I provide a figure of the head and pronotum (Fig. 2). 
Metolinus libertatis Bordoni, 2002

Examined MATERIAL. Philippines, Negros, Mt Canlaon, D. Mohagan II.2009, $1 \hat{\jmath}(\mathrm{cI}), 1 \uparrow(\mathrm{cB})$.

Note. This species was described from Panay (Libertad Fluss). New record for Negros. This is the first record since the description of the species.
Metolinus finettii sp. $\mathrm{n}$.

EXAmined MATERIal. Holotype $\delta^{\lambda}$ : Philippines, Palawan, San Vicente env., C. Finetti I.2009 (cB).

DESCRIPTION. Length of body $3.7 \mathrm{~mm}$; from anterior margin of head to posterior margin of elytra: $2.1 \mathrm{~mm}$. Body shiny, entirely light brown; antennae and legs
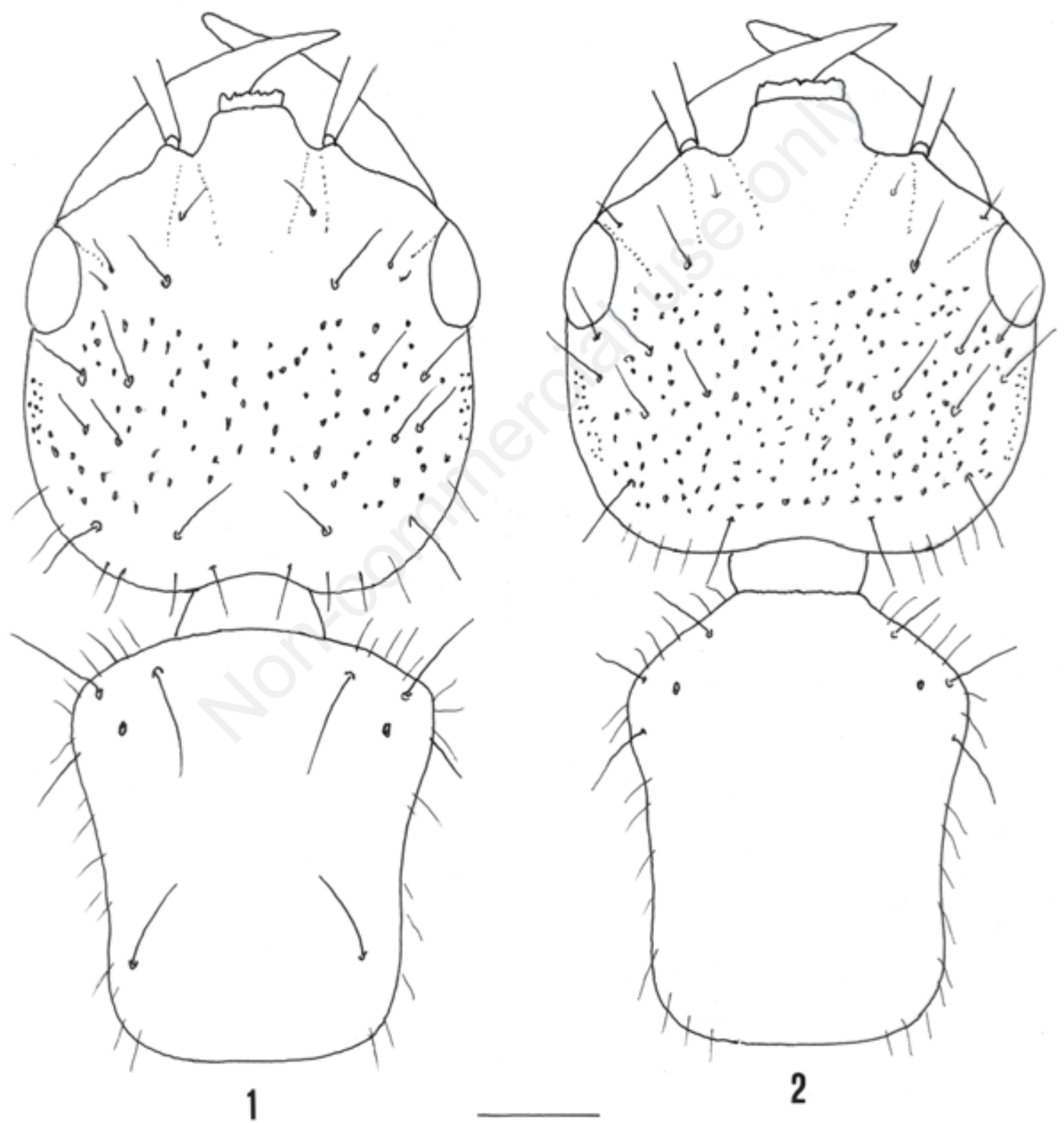

Figs. 1-2. Head and pronotum of: 1 - Thyreocephalus dustucheus Bordoni; 2 - Thyreocephalus omaleus Bordoni (scale bar: $0.5 \mathrm{~mm})$. 
yellowish-brown. Head quadrangular. Eyes large and protruding. Surface of head with traces of transverse micro-striation and very few, isolated punctures. Pronotum longer than head, anteriorly a little dilated where it is as wide as head, with oblique anterior margins and rounded sides. Surface with dorsal series of 3-4 fine punctures and lateral series of 2-3 very fine punctures. Elytra sub-rectangular, longer and a little wider than pronotum, with sub-rectilinear an sub-parallel sides, and rounded humeral angles. Surface with very fine, sparse puncturation arranged in three series, one near the suture, one median and one lateral. Abdomen without micro-sculpture, with very fine and very sparse puncturation on the sides.

Tergite and sternite of the male genital segment as in Figs 3-4. Aedeagus (Fig. 5) $0.74 \mathrm{~mm}$ long, with large median lobe; parameres long and narrow; inner sac with two basal, long spines, a median series of short, little spinulae and a group of distal spines.

ETymology. Patronymic. The species is dedicated to the friend Claudio Finetti (Siena) who collected the specimen.

Distribution. The species is known only from the type locality.

Note. In the external characters this species is closely related to $M$. chanthaburiensis Bordoni, 2002 from Thailand and M. quadriceps Bordoni, 2002 from Malaysia and Sumatra, but differs by the structure of the inner sac of the aedeagus.

The genus Metolinus Cameron, 1920 is certainly the most representative genus of the Oriental Region, composed of more than 100 species. Apart from very few taxa, species of Metolinus seem rather localized and linked to various stages of decay of trees.

\section{Metolinus cleopatranus sp. $\mathrm{n}$.}

EXAMINED MATERIAL. Holotype $\delta$ : Philippines, Palawan, Cleopatra Needle N. P., Tanabank riv. val., 300 m, Bolm 20-22.XII.1990 (NHMB).

DESCRIPTION. Length of body $4.2 \mathrm{~mm}$; from anterior margin of head to posterior margin of elytra: $2.2 \mathrm{~mm}$. Body shiny. Head and abdomen brown black, pronotum and elytra reddish-brown; antennae and legs pale testaceous. Head sub-quadrate, a little dilated forward and with slightly rounded sides. Eyes large and protruding. Surface of head with a few traces of transverse microstriation and a few, fine, sparse punctures. Pronotum longer and narrower than head, with broadly rounded anterior angles and slightly sinuate sides. Surface with dorsal series of 5 punctures and lateral series of 5 finer, median punctures. Elytra long, longer and wider than pronotum, dilated posteriad, with rounded humeral angles. Surface with fine, sparse punctures, arranged in three series, one near the suture, one median and one lateral. Abdomen without micro-sculpture, with few, fine punturation on the sides.

Sixth visible abdominal tergite as in Fig. 6. Posterior margin of the 6th visible sternite with a median lobule (Fig. 7). Tergite and sternite of the male genital segment as in Figs 8-9. Aedeagus (Fig. 10) 0.8 $\mathrm{mm}$ long, with large median lobe; parameres short; inner sac characterized by a group of distal spines, followed by a left series of large scales and by a right long, narrow spine.

ETyMology. The specific epithet refers to the type locality.

Distribution. The species is known only from the type locality.

Note. For the external characters this species are similar to those of M. heuresilogus Bordoni, 2002 from Thailand; the new species differs by the structures of inner sac of the aedeagus.

Metolinus elegans sp. n.

EXAmined Material. Holotype $\delta^{\lambda}$ : Philippines, Mindanao, $30 \mathrm{~km} \mathrm{~W}$ Maramag, $1600 \mathrm{~m}$, Bolm 2830.XII.1990 (NHMB).

DESCRIPTION. Length of body $4.4 \mathrm{~mm}$; from anterior margin of head to posterior margin of elytra: $2.3 \mathrm{~mm}$. Body shiny. Head and abdomen black, pronotum and elytra reddish-brown; antennae yellowish; legs brown with yellowish tarsi. Head sub-rectangular, a little longer than broad, a little dilated forward, with largely rounded posterior angles. Eyes medium-sized and protruding. Surface of head with a few traces of transverse micro-striation, and a few, fine punctures. Pronotum sub-rectangular, longer and narrower than head, with oblique anterior margins and slightly sinuate sides. Surface with dorsal series of 5 well visible, spaced punctures and lateral series of 3 median punctures. Elytra sub-rectangular, long, longer and wider than pronotum, with sub-rectilinear sides and rounded humeral angles. Surface with fine, sparse puncturation, arranged in three series, one near the suture, one median and one lateral. Abdomen with traces of transverse micro-striation, and fine, very sparse puncturation on the sides.

Posterior margin of the 6th visible male tergite and sternite with a median lobule (Figs 11-12). Tergite and sternite of the male genital segment as in Figs 1314. Aedeagus (Fig. 15) $0.77 \mathrm{~mm}$, with broad median 

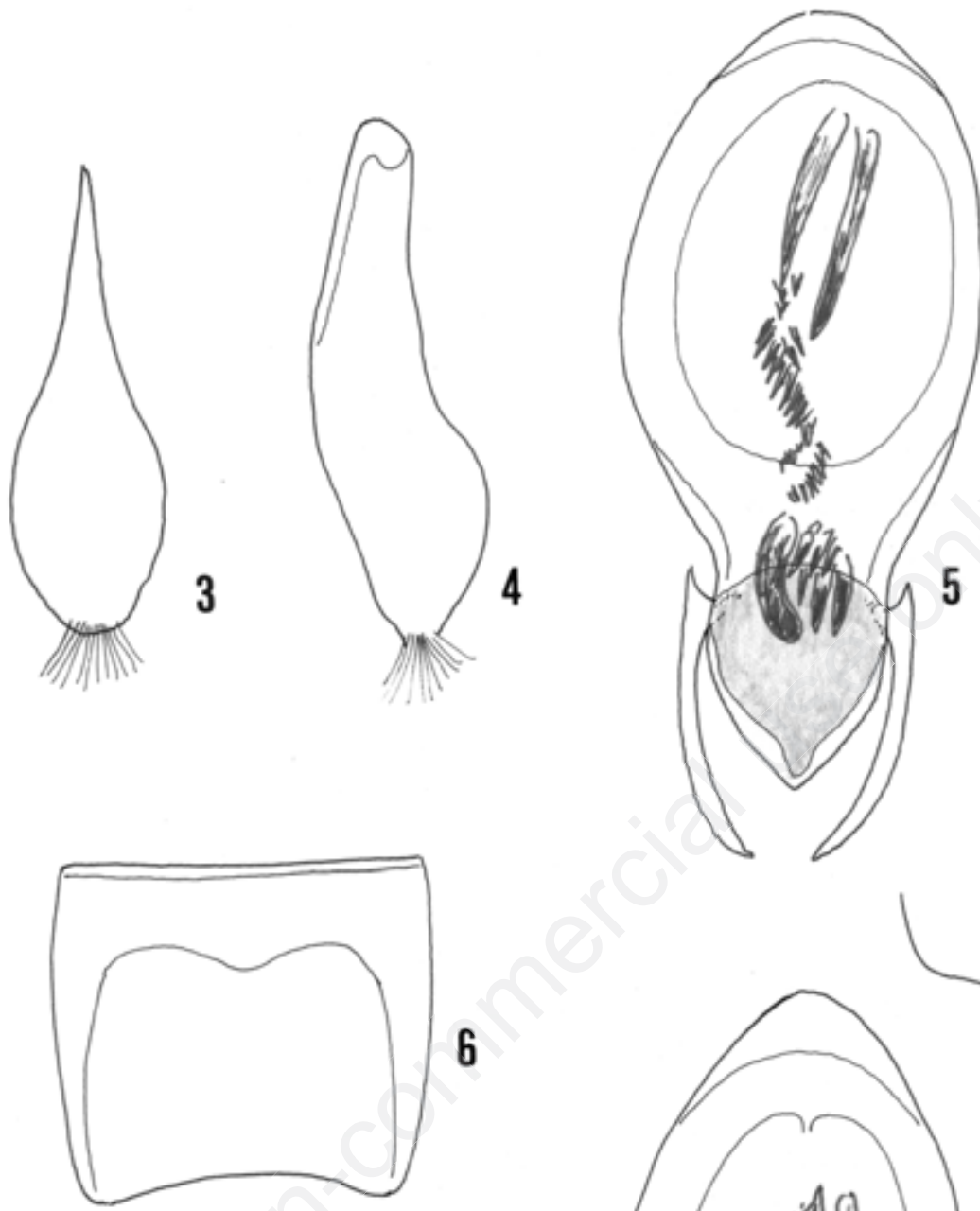

6

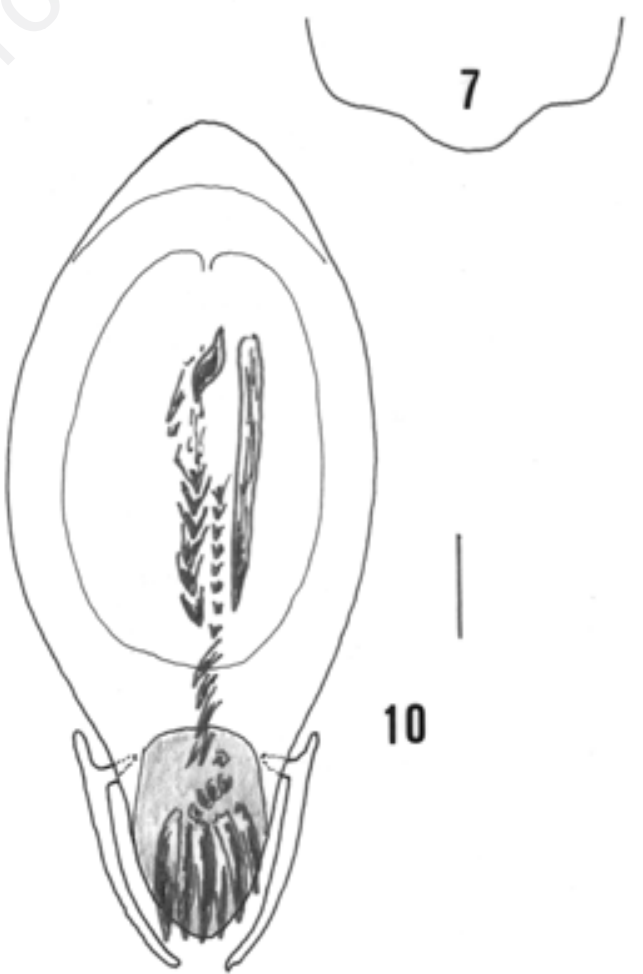

Figs. 3-10. Metolinus finettii sp. n.: 3 - tergite, 4 - sternite of the male genital segment, 5 - aedeagus. Metolinus cleopatranus sp. n.: $6-6^{\circ}$ visible male tergite, $7-6^{\circ}$ visible male sternite, $8-$ tergite and $9-$ sternite of the male genital segment, $10-$ aedeagus (scale bar: $0.1 \mathrm{~mm}$ ). 
lobe; parameres short; inner sac with 5 long spines. Eтymology. The specific epithet is the Latin elegans (elegant).

Distribution. The species is known only from the type locality.

NoTE. For the external characters this species are similar to the closely related M. fruhstorferi Bordoni, 2002 from Sulawesi from which the new species differs by the structure of inner sac of the aedeagus.

\section{Metolinus insularis sp. $\mathrm{n}$.}

Examined material. Holotype $\delta$ : Philippines, Mindanao, $30 \mathrm{~km} \mathrm{~W}$ Maramag, $1600 \mathrm{~m}$, Bolm 2830.XII.1990 (NHMB).

DESCRIPTION. Length of body $5.3 \mathrm{~mm}$; from anterior margin of head to posterior margin of elytra: $2.6 \mathrm{~mm}$. Body shiny, brownish-black with yellowish tarsi. Head sub-rectangular, narrow forward, with rounded sides. Eyes medium-sized and very little protruding. Surface of head with traces of transverse micro-striation, and fine, sparse punctures. Pronotum massive, long, longer than head and as wide as head, with almost rectilinear sides, slightly oblique anterior margins and narrowly rounded anterior angles. Surface with dorsal series of 5 punctures and lateral series of 3 median punctures. Elytra large, sub-rectangular, longer and wider than pronotum, with sub-rectilinear and sub-parallel sides and rounded humeral angles. Surface with fine, sparse puncturation, arranged in three series, one near the suture, one median and one lateral. Abdomen with traces of polygonal micro-reticulation and fine, spaced puncturation on the sides.

Posterior margin of the 6 th visible, male tergite and sternite with a median lobule (Figs 16-17). Tergite and sternite of the male genital segment as in Figs 1819. Aedeagus (Fig. 20) $1 \mathrm{~mm}$ long, sub-spherical, with short median lobe and short and narrow parameres; inner sac with a distal, arched spine, followed by a proximal dark area between long spines.

Etymology. The specific epithet is the Latin insularis- $e$ (insular).

Distribution. The species is known only from the type locality.

Note. For the external characters this species is closely related to M. refixus Bordoni, 2002 from Thailand, but differs by the structure of inner sac of the aedeagus.

Phacophallus flavipennis (Kraatz, 1859)

Examined Material. Philippines, Negros, Mt Canla-

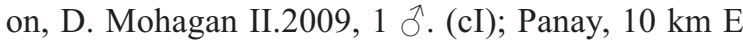
Sibalon, 100 m, Bolm 10.XII.1990, 1 ex. (NHMB); Palawan, Bahile, 50 m, Bolm 22.XII.1992, 1 ex. (cB); Palawan, Port Barton, 150 m, Bolm 14-18.I.1990, 5 exx. (NHMB), 1 ex. (cB); Palawan, Cleopatra Needle N. P., Tanabank riv. val., $300 \mathrm{~m}$, Bolm 2022.XII.1990, 1 ex. (cB); Mindanao, Maramag Prov., Portulin, 1700 m, Bolm 3.I.1991, 7 exx. NHMB), 2 exx. (cB); same data, $30 \mathrm{~km}$ W Maramag, Bolm 1418.XII.1990, 2 exx. (NHMB), 1 ex. (cB).

Note. This species is known from the Indian, Indochinese and Indomalayan sub regions (Bordoni, 2002). New records for Panay, Palawan, and Mindanao.

Phacophallus pallidipennis (Motschulsky, 1858) EXAmined Material. Philippines, N Palawan, Bahile, 50 m, Bolm 22.XII.1992, 7 exx. (NHMB).

Note. This species is very widespread in the Oriental region from Sri Lanka to China and the Philippines (Bordoni, 2002). New record for Palawan.

\section{Erymus elytratus $\mathrm{sp} . \mathrm{n}$.}

Examined Material. Holotype ${ }^{\lambda}$ : Philippines, Mindanao, $30 \mathrm{~km} \mathrm{~W}$ Maramag, $1600 \mathrm{~m}$, Bolm 2830.XII.1990 (NHMB); paratypes: same data, 1 ㅇ (NHMB), 1 \& (cB).

DESCRIPTION. Length of body $4.5 \mathrm{~mm}$; from anterior margin of head to posterior margin of elytra: $2.3 \mathrm{~mm}$. Body shiny, reddish brown with infuscate head. Head ovoid-elongate, with large and protruding eyes. Surface of head with few, spaced, fine punctures. Pronotum longer than head, dilated forward where it is as wide as head, with oblique anterior margins, rounded anterior angles, and a slightly sinuate sides. Surface with dorsal series of 4 fine, widely spaced punctures and lateral series of 4 anterior punctures. Elytra long, sub-rectangular, longer and wider than pronotum, with sub-rectilinear and sub-parallel sides and rounded humeral angles. Surface with very fine, sparse puncturation arranged in some series. Abdomen with fine, transverse micro-striation and fine, very spaced puncturation on the sides.

Tergite and sternite of the male genital segment as in Figs 21-22. Aedeagus (Fig. 23) $0.6 \mathrm{~mm}$ long, sub-spherical, with particularly long parameres; inner sac apparently not visible.

ETymology. The specific epithet is the Latin elytratus- $a$ - um in relation to the long elytra.

Distribution. The species is known only from the type locality.

Note. The external characters show that this species is 

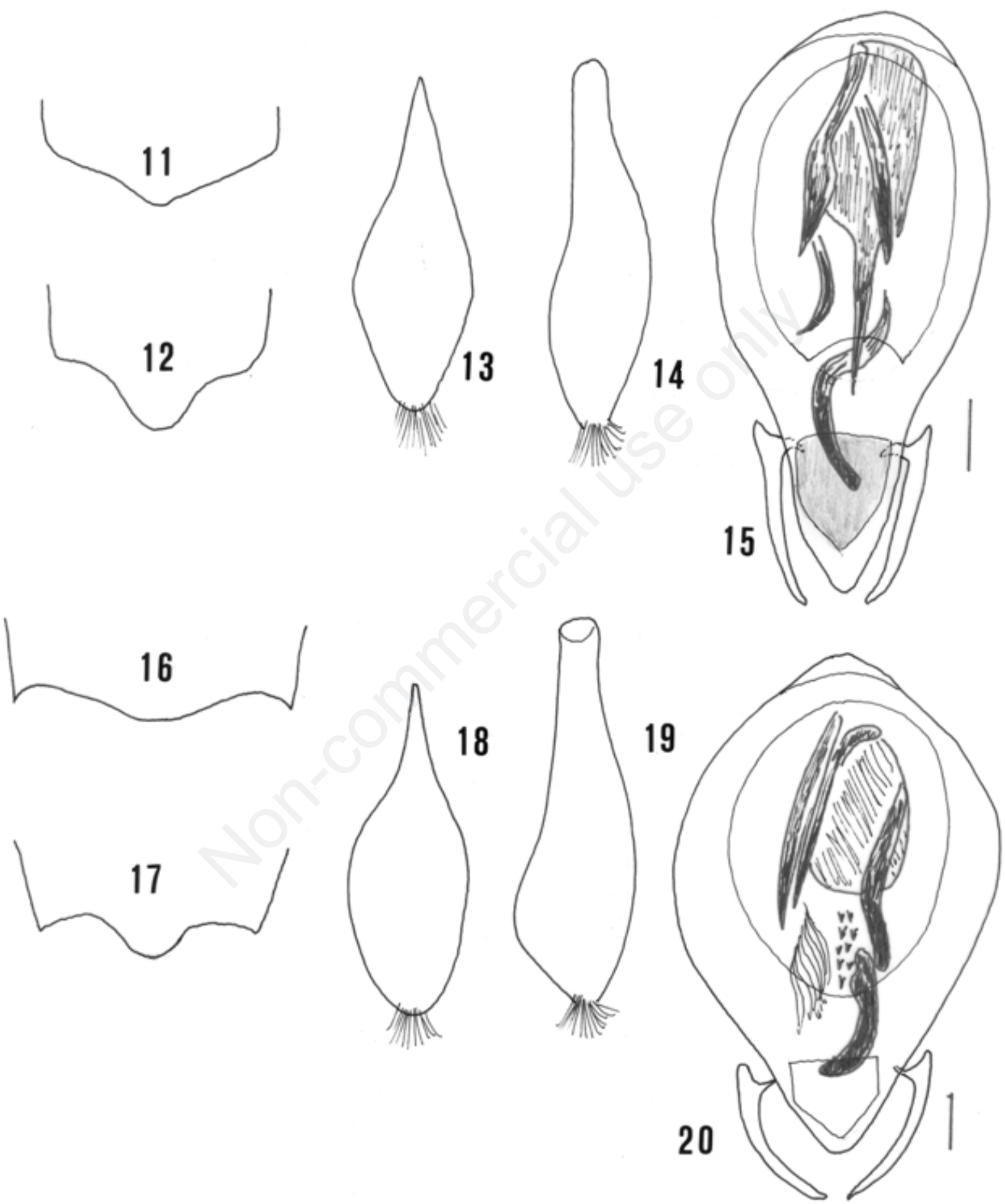

Figs. 11-20. Metolinus elegans sp. n.: $11-6^{\circ}$ visible male tergite, $12-6^{\circ}$ visible male sternite, $13-$ tergite and $14-$ sternite of the male genital segment, 15 - aedeagus. Metolinus insularis sp. n.: $16-6^{\circ}$ visible male tergite, $17-6^{\circ}$ visible male sternite, 18 - tergite and 19 - sternite of the male genital segment, 20 - aedeagus (scale bar: $0.1 \mathrm{~mm}$ ). 
closely related to E. gracilis (Fauvel, 1895), which is very widespread in the Oriental region (Bordoni, 2002); it differs in the puncturation of pronotum, shape of elytra, and genitalia. In particular the parameres are longer, the distal pore is very broad and the inner sac is invisible. This is the first species of the genus Erimus Bordoni, 2002 collected in the Philippines.

\section{Xanthophius philippinus sp. $\mathrm{n}$.}

EXAMINED MATERIAL. Holotype $\delta^{\uparrow}$ : Philippines, SW Panay, 8 km E Bontol, 200 m, Bolm 10-11.XII.1990 (NHMB).

DESCRIPTION. Length of body $4 \mathrm{~mm}$; from anterior margin of head to posterior margin of elytra: $2.2 \mathrm{~mm}$. Body shiny, slender, entirely yellowish brown light, with feebly infuscate head. Head sub-rectangular elongate, with a little rounded sides and largely rounded posterior angles. Eyes medium-sized, very protruding. Surface of head with evident puncturation, the distance between the punctures equal to two time their diameter. Pronotum slender, narrow, longer and narrower than head, with oblique anterior margins and almost not sinuate sides. Surface with dorsal series of 8-9 punctures and lateral series of 5-6 punctures. Elytra long, sub-rectangular, a little wider than pronotum, as long as it, with sub-rectilinear and sub-parallel sides and rounded humeral angles. Surface with very fine, spaced puncturation, arranged in some, spaced series. Abdomen without micro-sculpture, with fine puncturation on the sides.

Tergite and sternite of the male genital segment as in Figs 24-25. Aedeagus (Fig. 26) $0.9 \mathrm{~mm}$ long, with particular parameres; inner sac with numerous spines.

Etymology. The specific epithet refers to the Philippines.

Distribution. The species is known only from the type locality.

Note. This species resembles the Philippine species E. benguetensis Bordoni, 2002 (Luzon and Negros). $X$. philippinus differs from that species by the lighter colouration, sparser puncturation of head, the shape and puncturation of pronotum and the genitalia.

\section{Manilla rufula sp. n.}

Examined Material. Holotype $\delta$ : Philippines, Mindanao, $30 \mathrm{~km} \mathrm{~W}$ Maramag, $1600 \mathrm{~m}$, Bolm 2830.XII.1990 (NHMB).

DESCRIPTION. Length of body $7.3 \mathrm{~mm}$; from anterior margin of head to posterior margin of elytra: $4 \mathrm{~mm}$.
Body shiny, brown amaranth; antennae brown light; legs yellowish pale. Head ovoid-elongate, with obsolete posterior angles. Eyes medium-sized, almost flat. Surface of head with 4 infra-ocular punctures and a few, sparse punctures on the posterior half. Pronotum sub-rectangular, long, longer than head, as wide as it, with very oblique anterior margins, obsolete anterior angles, and sub-rectilinear sides. Surface with dorsal series of 6 clearly visible punctures and lateral series of 4-5 punctures. Elytra massive, sub-rectangular, longer and wider than pronotum, with sub-rectilinear and sub-parallel sides, and rounded humeral angles. Surface with fine, sparse puncturation, arranged in three series, one near the suture, one median and one lateral. Abdomen without micro-sculpture, with few, fine but well visible puncturation.

Sixth visible tergite with rounded posterior margin. Tergite and sternite of the male genital segment as in Figs 27-28. Aedeagus (Fig. 29) $1.77 \mathrm{~mm}$ long, ovoid, membranous, transparent, with very small parameres; inner sac with a series of short, small spines.

ETymology. The specific epithet is the Latin rufulusa- um (reddish).

Distribution. The species is known only from the type locality.

Note. This species differs from its congeners in the Philippines by its size, colouration and genitalia.

\section{Manilla maramag sp. $\mathrm{n}$.}

EXAmined Material. Holotype $\delta^{\top}$ : Philippines, Mindanao, $30 \mathrm{~km} \mathrm{~W}$ Maramag, $1600 \mathrm{~m}$, Bolm 2830.XII.1990 (NHMB).

DESCRIPTION. Length of body about $5 \mathrm{~mm}$; from anterior margin of head to posterior margin of elytra: $2.7 \mathrm{~mm}$. Body shiny, reddish-brown, with yellowish humeral angles and pale yellowish legs. Head subrectangular, a little dilated forward, with very broadly rounded posterior angles. Eyes medium-sized and protruding. Surface of head with 4 intraocular punctures and few, isolated punctures on the posterior half. Pronotum longer and a little wider than head, with very oblique anterior margins, obsolete anterior angles and sinuate sides. Surface with dorsal series of 6 superficial, broad punctures and lateral series of 4 similar punctures. Elytra broad, shorter and wider than pronotum, with broadly rounded humeral angles. Surface with fine, widely spaced punctures, arranged in three series, one near the suture, one median and 


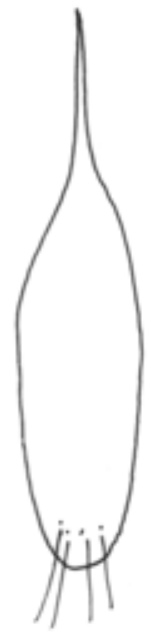

21

22
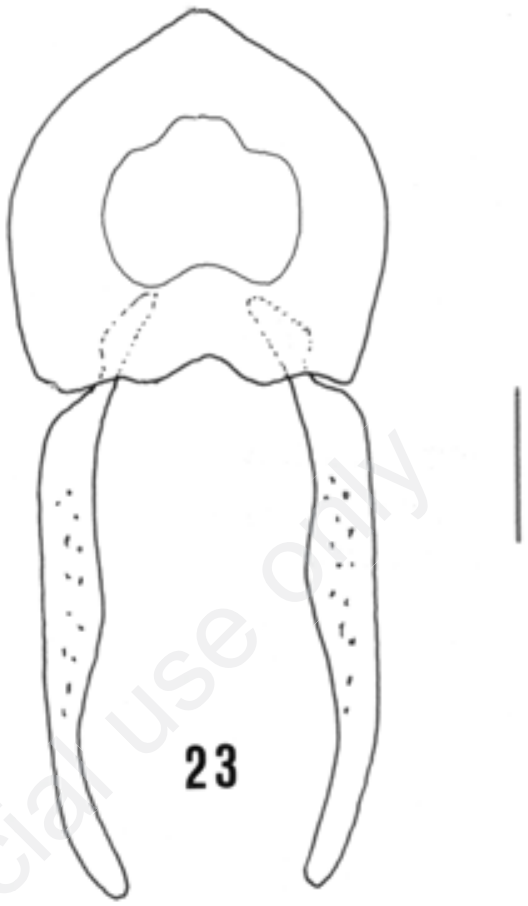

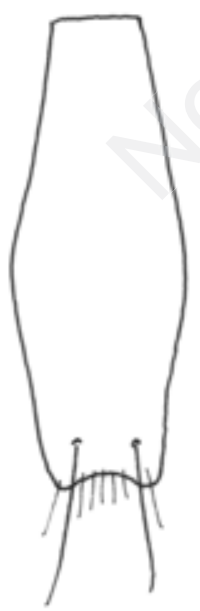

24

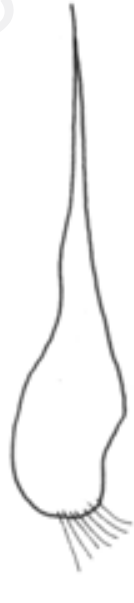

25

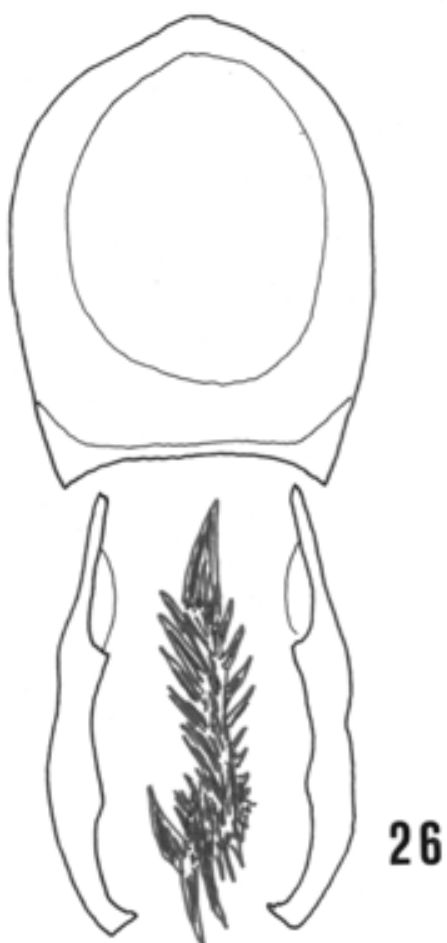

Figs. 21-26. Erymus elytratus sp. n.: 21 - tergite and 22 - sternite of the male genital segment, 23 - aedeagus. Xanthophius philippinus sp. n.: 24 - tergite and 25 - sternite of the male genital segment, 26 - aedeagus (scale bar: $0.1 \mathrm{~mm}$ ). 


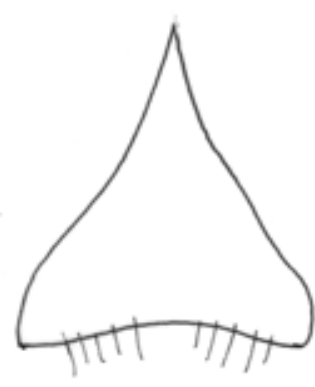

27

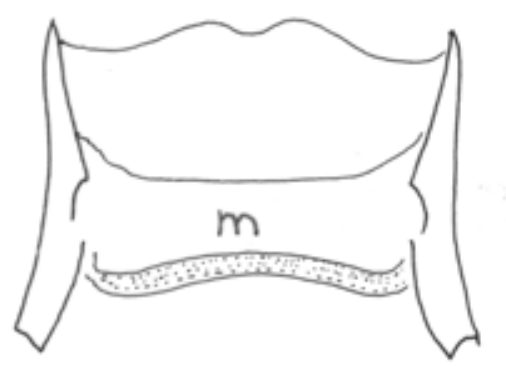

28
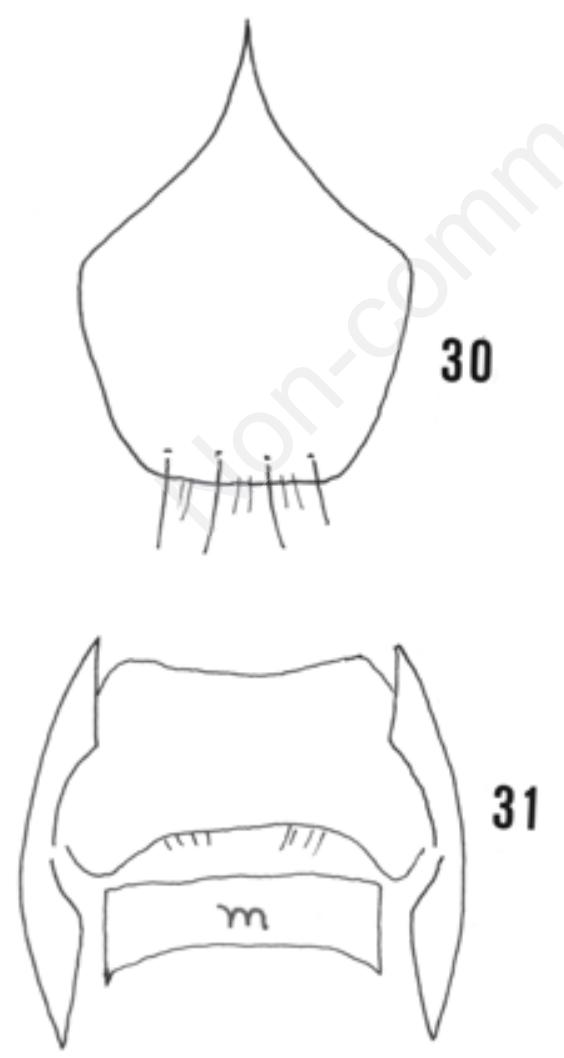

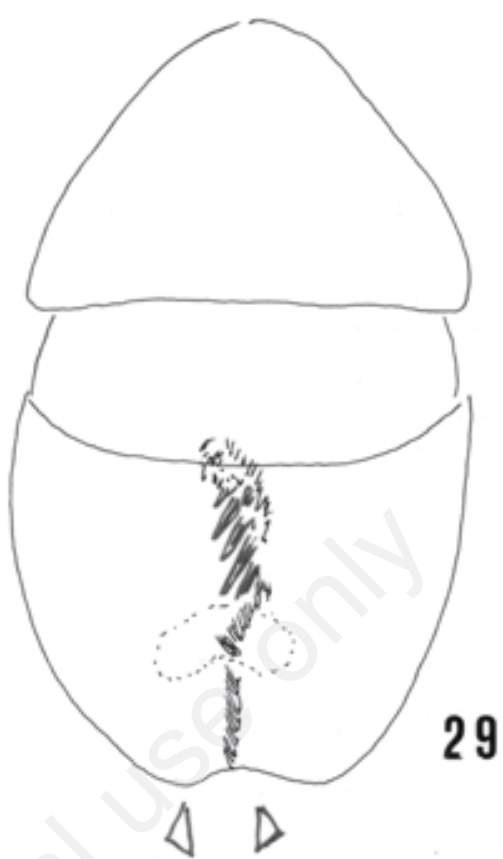

29

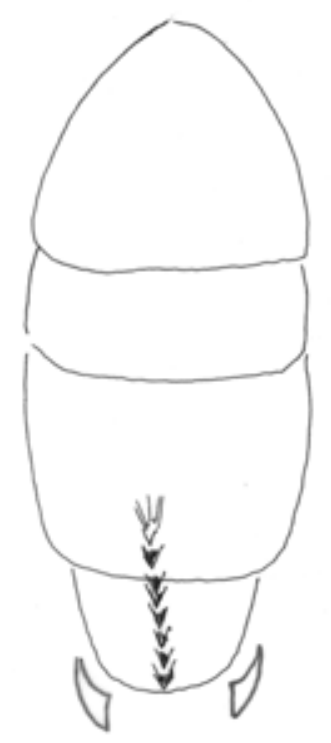

32

Figs. 27-32. Manilla rufula sp. n.: 27 - tergite and 28 - sternite of the male genital segment, 29 - aedeagus. Manilla maramag sp. n.: 30 - tergite and 31 - sternite of the male genital segment, 32 - aedeagus (m: membranous portion) (scale bar: $0.1 \mathrm{~mm}$ ). 
one lateral. Abdomen without micro-sculpture, with few, fine puncturation on the sides.

Sixth visible tergite with rounded posterior margin. Tergite and sternite of the male genital segment as in Figs 30-31. Aedeagus (Fig. 32) $0.55 \mathrm{~mm}$ long, very transparent, membranous, ovoid, narrow and long, with very small parameres; inner sac narrow and short, covered with short, fine spinulae.

ETymology. The specific epithet refers to the type locality, as a noun in apposition.

Distribution. The species is known only from the type locality.

NoTE. The external characters show that this species is related to M. misamisae Bordoni, 2002 from Mindanao and Luzon; from this it differs by the shorter body, broader pronotum, shorter elytra and by the genitalia. The aedeagus is similar to that of $M$. montanella Bordoni, 2002 from Luzon and M. sungei Bordoni, 20020 from Malaysia but differs by the male genital segment, shape of parameres and inner sac.
I consider interesting to informing that he had found in the genital segment and around the aedeagus very numerous fungal spores and a hypopus nymph of a mite Tarsonemidae (with the help of Dr. R. Nannelli, Centro di ricerca per l'Agrobiologia a la Pedologia, Cascine del Riccio, Firenze). The most species of this family feed on the thin-walled mycelia of fungi and often uses insects to phoresy.

\section{ACKNOWLEDGEMENTS}

I wish to thank the colleagues who made possible the writing of this contribution to one of the most interesting but least studied areas of the Oriental Region concerning Xantholonini: Luca Bartolozzi (Museo Zoologico "La Specola" dell’Università di Firenze, Italy), Matthias Borer (Naturhistorishes Museum, Basel, Switzerland), and Tateo Ito (Kyoto, Japan). I thank also Guillaume de Rougemont (Oxford) for the control of the English language.

\section{REFERENCES}

Bernhauer M., 1912 - Neue Staphyliniden der Philippinen. The Philippine Journal of Sciences, Manila, 7 (4): $245-254$.

Bernhauer M., 1916 - Neue Staphyliniden des indo-malaiischen Faunengebietes, besonders der Philippinen. Verhandlungen der k. k. zoologisch-botanischen Gesellschaft in Wien, 66: 418-431.

Bernhauer M., 1919 - Neue Staphyliniden der Philippinen. Deutsche Entomologische Zeitschrift, 359-365.

Bordoni A., 1990 - Studi sugli Xantholinini della Regione Orientale: il genere Manilla gen. n. (Coleoptera, Staphylinidae). In: Berti N. (ed.), Miscellanées sur les Staphylins. Mémoires du Muséum national d'Histoire naturelle, Paris, A: 171-180.

Bordoni A., 2002 - Xantholinini della Regione Orientale (Coleoptera: Staphylinidae). Classificazione, filogenesi e revisione tassonomica. Monografie del Museo regionale di Scienze naturali, Torino, 33: $998 \mathrm{pp.}$

CAmeron M., 1920 - New species of Staphylinidae from India. (1). The Entomologist's Monthly Magazine, 56(6): 141-148.

CAmeron M., 1941 - New species of Staphylinidae (Col.) from the Philippines. Annals and Magazine of Natural History, 11(7): 430-447.

Cameron M., 1944 - Some observations on the Staphylinidae of the Broun Collection of Coleoptera in the British Museum, with description of new genera and species. Annals and Magazine of Natural History, 11(11): 779-793.

CoIffait H., 1956 - Les Xantholinitae de France et des régions voisines (Col. Staphylinidae). Revue française d'entomologie, 23: 31-75.

ERICHSON W.F., 1839 - Genera et species Staphylinorum insectorum coleopterorum familiae. F.H. Morin, Berlin, 954 pp.

Fauvel A., 1877 - Les Staphylinides de l'Australie et de la Polynésie. Annali del Museo civico di Storia naturale di Genova, 10: $168-297$.

Fauvel A., 1878 - Les staphylinides des Moluques et de la Nouvelle Guinée. Annali del Museo civico di Storia Naturale, Genova, 12: 171-315.

Fauvel A., 1879 - Les Staphylinides des Moluques et de la Nouvelle Guinée. Annali del Museo civico di Storia naturale di Genova, 15: 63-121.

Fauvel A., 1895 - Staphylinides nouveaux de l'Inde et de la Malaisie. Revue d'Entomologie: 180-286.

GuÉRIN MÉnEVILle F.E., 1844 - Description de quelques coléoptères de la Nouvelle-Grenade. Revue de Zoologie: 8-19.

JACQUELIN Du VAL P.N.C., 1857 - Genera des Coléoptères d'Europe. Paris, 2: 41-96.

MotsChUlSKY V., 1858 - Enumération des nouvelles espèces des Coléoptères rapportés de ses voyages par M. Victor Motschulsky. Bulletin de la Société Impérial des Naturalistes de Moscou, 31(3): 204-264.

RedtenBACHer L., 1867 - Reise der Österreichischen Fragatte Novara um die Erde in den Jahren 1857, 1859 unter den Befehlen des Commodore B. von Wüllerstorf-Urbair. Zoologischer Theil. Vol. 2. I. Abtheilung. A. Coleoptera. Wien, K. Gerold's Sohn, 249 pp. 